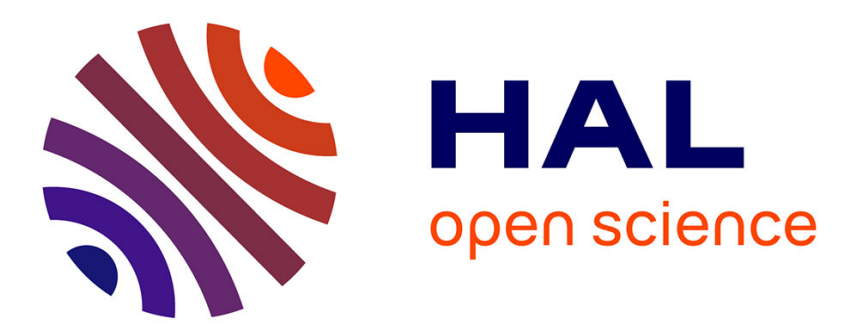

\title{
Original test device for crack propagation in the weld nugget of advanced high strength steels
}

Rémi Lacroix, Guillaume Kermouche, Arnaud Lens, Jean-Michel Bergheau, Helmut Klöcker

\section{- To cite this version:}

Rémi Lacroix, Guillaume Kermouche, Arnaud Lens, Jean-Michel Bergheau, Helmut Klöcker. Original test device for crack propagation in the weld nugget of advanced high strength steels. Engineering Fracture Mechanics, 2015, 138, pp.156-168. 10.1016/j.engfracmech.2015.02.022 emse-01500896

\section{HAL Id: emse-01500896 \\ https://hal-emse.ccsd.cnrs.fr/emse-01500896}

Submitted on 10 Dec 2019

HAL is a multi-disciplinary open access archive for the deposit and dissemination of scientific research documents, whether they are published or not. The documents may come from teaching and research institutions in France or abroad, or from public or private research centers.
L'archive ouverte pluridisciplinaire HAL, est destinée au dépôt et à la diffusion de documents scientifiques de niveau recherche, publiés ou non, émanant des établissements d'enseignement et de recherche français ou étrangers, des laboratoires publics ou privés. 


\title{
Original test device for crack propagation in the weld nugget of advanced high strength steels
}

\author{
Rémi Lacroix ${ }^{a}$, Guillaume Kermouche ${ }^{a}$, Arnaud Lens ${ }^{b, 1}$, Jean Michel Bergheau ${ }^{c}$, \\ Helmut Klöcker ${ }^{\mathrm{a}, *}$

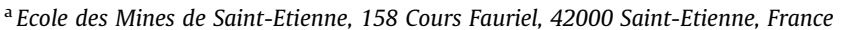 \\ ${ }^{\mathrm{b}}$ ArcelorMittal Maizières RED Automotive Products, SA Voie Romaine, 57280 Maizières-Lès-Metz, France \\ ${ }^{\mathrm{c}}$ Université de Lyon, ENISE, LTDS, UMR 5513 CNRS/ECL/ENISE, 58 rue J. Parot, 42023 Saint-Etienne Cedex 2, France
}

\begin{abstract}
Advanced High-Strength Steels are ever increasingly used in industry, and unlike mild steels the crack propagates through the weld nugget. At the present time, any method to measure the strength of the fusion zone is unavailable.

Therefore a new test setup enforcing crack propagation through the weld nugget was developed. In the wedge test proposed, this device provides stable crack growth as the wedge is displaced. Thus, along with in situ observations, this device, without any prior assumptions is able to measure energy dissipation rate as well as crack opening angle. This is very significant because from these two data, a mechanical modeled was established to predict the cohesive energy and strength in the weld nuggets of AHSS. This method: the experimental setup and mechanical model were then applied to commercial alloys and synthetic grades successfully. This indicates that this methodology can be applied to any type of alloy.
\end{abstract}

\section{Introduction}

Faced with increasing fuel economy standards, safety concerns and environmental issues, the challenge in the automotive industry has been to lighten vehicles. Advanced High-Strength Steels (AHSS) play a significant role in this endeavor as they reduce weight while at the same guaranteeing a better passenger safety, ie higher energy absorption during crashes. Failures when using spot welding with AHSS is a sophisticated problem with high alloying, unstable phases in the microstructure, and what concerns our work crack propagation through the weld nugget or fusion zone.

Generally, Spot weld failures are broadly classified into two categories [1] as button pullout where the weld nugget withdraws completely from the sheet metal or interfacial in which the crack propagates through the weld nugget itself. The latter is not an issue when Spot welding mild steels since there are no full interfacial failures. Advanced High Strength Steels are such an improvement in material that they can fail by full interfacial failure, i.e. crack propagation through the fusion zone. Thus, a test to characterize this failure mode is fundamental. Even though there is a pressing need, the cross tensile test used to characterize spot welds industrywide cannot characterize the energy needed to initiate and propagate a crack in the fusion zone of a spot weld. As will be presented later in this article, the test set up developed in this work will be able to

\footnotetext{
* Corresponding author. Tel.: +33 3477420078 .

E-mail address: klocker@emse.fr (H. Klöcker).

1 Present address: ArcelorMittal Montataire Global R\&D, BP 30109, 1 route de Saint Leu, 60761 Montataire Cedex, France.
} 


\section{Nomenclature}

$\begin{array}{ll}a & \text { crack length } \\ A & \text { crack area } \\ \text { AHSS } & \text { Advance High Strength Steel } \\ b & \text { specimen width (perpendicular to the wedge direction) } \\ b_{n} & \text { spot weld dimension (perpendicular to the wedge direction) } \\ C & -\mathrm{d} \pi / \mathrm{d} A \\ \text { CTOA } & \text { Crack Tip Opening Angle } \\ d & \text { spot weld dimension (parallel to the wedge direction) } \\ F & \text { opening load } \\ f & \text { friction coefficient between the wedge and the sample } \\ F_{h} & \text { horizontal load acting on the specimen } \\ F_{\text {wedge }} & \text { total load applied to the wedge } \\ \text { FZ } & \text { Fusion Zone } \\ \text { HAZ } & \text { Heat Affected Zone } \\ L & \text { sample length (parallel to the wedge direction) } \\ R & \text { energy dissipation rate } \\ R_{\text {global }} & \text { global value of the energy dissipation rate } \\ R_{\text {stable }} & \text { energy dissipation rate during stable crack propagation } \\ R_{\text {unstable }} & \text { energy dissipation rate during unstable crack propagation } \\ t & \text { sheet thickness } \\ u & \text { half the opening displacement } \\ u_{\text {wedge }} & \text { wedge displacement } \\ U_{e} & \text { elastic energy } \\ U_{d} & \text { dissipated energy } \\ \Gamma_{\text {coh }} & \text { fracture energy } \\ \pi & \text { potential energy } \\ \sigma_{\text {coh }} & \text { fracture stress } \\ \sigma_{0} & \text { yield stress }\end{array}$

do just that. The following is a brief survey of the literature to present some background and to position better this paper's contribution.

In brittle materials, unlike AHSS, crack prorogation is fairly easy to model. The Griffith-Orowan theory [2] describes the mechanics of the fracture process sufficiently for engineering purposes in these materials. In ductile materials it is more complicated, crack initiation is well described by the J-integral, but not crack propagation. By idealizing elastic-plastic deformation as nonlinear elastic, the J-integral concept [3] provided the basis for extending fracture mechanics methodology well beyond the limits of validity for linear elastic fracture mechanics (LEFM). But stable crack growth causes local unloading which results in geometry dependent crack growth resistance curves. In addition, constraint loss during large scale plastic deformation leads to a breakdown of $J$ theory. Thus, under large crack propagation, $J$ is not the crack driving force $[3,4]$.

Turner [5,6] extended Griffith's approach to elasto-plastic materials for an incremental increase of the crack surface. The crack driving force is the variation of the potential energy. In Griffith's approach, the variation of the potential energy equals the fracture energy during stable crack extension. In elasto-plastic materials [5] the variation of the potential energy equals the total dissipated energy, i.e. the sum of the fracture energy and the energy dissipated in the plastic deformation. The energy dissipation rate $R$ is the derivative of the total dissipated energy with respect to the crack area.

Li and Turner [7] and Brocks et al. [8] analyzed the transferability of the $R$-value. They showed that $R$ cannot characterize long distance crack propagation. Cotterell et al. [9] assume, like Turner [5], that work to fracture a ductile specimen may be separated into two components: The essential work performed in the end region $\left(W_{\text {ess }}\right)$ and the work performed in the screening plastic region $\left(W_{p}\right): d U_{d}=W_{\text {ess }}+W_{p}$. Pardoen et al. [10] observed a linear relationship between $W_{\text {ess }}$ and the specimen thickness. The specific essential work of fracture may thus be determined by measuring $R$ on Double End Notched Tension specimens of different thickness [11]. Even if this method gives reliable results to determine the specific essential work of fracture, nevertheless, it is not applicable to spot welds because it is not possible to change the thickness of the sheet metal.

The Crack Tip Opening Angle (CTOA) is determined by the displacement of the crack lips at a given distance from the crack front. In most materials, crack propagation is characterized by a constant CTOA-value [12]. Heerens et al. [13] showed that for middle crack tension and compact specimens, the CTOA-value (ISO 22889:2007) are independent of the sample size. The critical Crack-Tip-Opening Angle (CTOA) was shown to be the most suited criterion for modeling stable crack growth and instability during the fracture process of homogeneous materials [14-17]. But, in thin sheet material, crack tunneling and slanting will lead to non-constant values of the CTOA [13,18]. Newman et al. [12] showed that the critical CTOA values should be established for various specimen configurations, crack lengths, and thicknesses. Unfortunately, spot welding of 
thin (about $2 \mathrm{~mm}$ thick) sheets leads to "small" volumes of the fusion zone, i.e. about $4 \times 8 \times 8 \mathrm{~mm}$. Ascertaining accurately the critical CTOA values for different specimen configurations and thicknesses is thus almost impossible. This is one of the reasons why a new test facility specifically designed for analyzing crack propagation in thin sheet metal is needed. Section 2 will describe the wedge test device developed.

Let's introduce some background required for mechanical modeling. Atkins et al. [19] demonstrated experimentally that crack propagation may not be explained by any single parameter depending on the crack length. Cohesive zone models initiated by Dugdale [20] and Barenblatt [21] can simulate a great deal of crack initiation and propagation. This approach assumes prior knowledge of two aspects of the material modeled (cohesive strength \& critical displacement or cohesive energy). Zhou et al. [22] depicted the load displacement curve for a peel test on a weldment. But these methods before their utilization require determining constants in the different volumes (base metal, Heat Affected Zone and Fusion Zone) of the assembly. Experimental resolution of cohesive strength and cohesive energy in a very small volume of material (HAZ) is practically impossible.

The above summary shows that crack initiation in ductile materials is well described by several criteria, but today no crack propagation criterion for ductile failure in spot weld assemblies is available to the best of our knowledge. In the work presented, we have been able to characterize experimentally the crack propagation in the fusion zone material of spot welds. This is a novel nuts and bolts physical method that does not rely on theory or simulation but on an actual laboratory device designed specifically for this purpose. This aforementioned wedge test directly measures in-situ the energy dissipation rate $R$ and the Crack Tip Opening Angle (CTOA). Stable crack propagation is characterized by constant values of the energy dissipation rate and the CTOA. Evidently, as tests and results accumulate, theory and simulation will follow. The paper is organized as follows: as aforementioned Section 2 titled Experimental, is devoted to the wedge test device developed. Section 3 presents the mechanical model. Section 4 concerns the results. First, the new experimental wedge test gives pertinent and reliable measurements. Second, the mechanical model shows that this test method is transferable. In other words, the test device can be used in other configurations and geometries. Finally the conclusions and some future work will be discussed.

\section{Experimental}

\subsection{Experimental set-up}

\subsubsection{The test jig}

Various wedge tests have been proposed in the literature to delineate resistance to crack growth. The present test was particularly designed for crack propagation in sheet metal as suggested by David Embury [25], and from previous technical savoir faire as well as trial and error. A60 degrees-wedge is driven in between the two welded sheets into the existing seam, while the opposite side forms a hinge-type stop which blocks only the translation movement of the sample while not impeding the splitting of the sample. The specimen can still pivot or rotate. Fig. 1a shows the experimental set up with a sample. The load applied to the wedge and displacements are recorded continuously and correlated with the crack length from optical observation.

\subsubsection{Sample for wedge indentation}

An assembly of two stacked coupons welded in their center, as shown in Fig. 1a, is the source for two test specimens. This assembly is then split, sectioning the welded coupons as illustrated in Fig. 1b. The sectioned surface exhibits thus two notches delimiting the bond's surface between the sheets. This area will be observed during the progressive failure of the interface (Fig. 1a). An asymmetric sectioning crosscut is performed, leaving the split section, up to the weld much longer than the remainder. This long slice is about $25 \mathrm{~mm}$, while the rest is about $2 \mathrm{~mm}$.

\subsubsection{Macroscopic analysis of the wedge test}

The load applied to the wedge $\left(F_{\text {wedge }}\right)$ and wedge displacement $\left(u_{\text {wedge }}\right)$ are recorded continuously. The load applied to the sample is controlled by both the wedge angle $(\alpha)$ and the friction coefficient $f$ (Fig. 2). Friction loads are always in the opposite direction of the wedge's movement. The following relations result from simple equilibrium considerations:

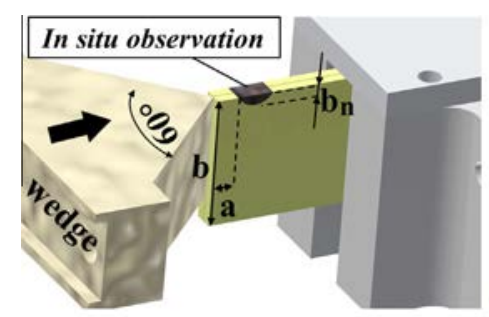

(a)

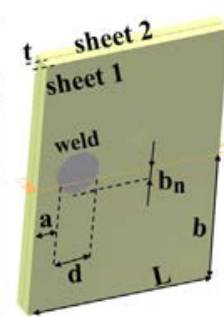

(b)

Fig. 1. Principle of the wedge test. (a) load applied during the wedge test (b) preparing a specimen from a spot weld. 


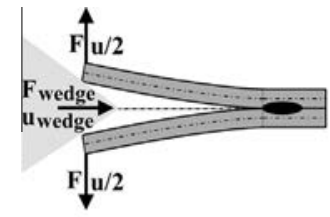

(a)

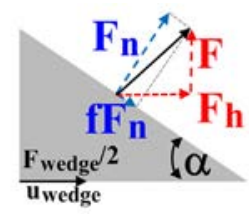

(b)

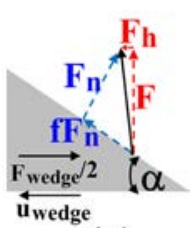

(c)

Fig. 2. The wedge test: (a) schematic representation of the wedge indentation, Load transmission during loading (b) and unloading (c).

$$
\begin{array}{ll}
\text { loading } & \text { unloading } \\
\mathrm{F}=\frac{\cos (\alpha)-f \sin (\alpha)}{\sin (\alpha)+f \cos (\alpha)} \frac{F_{\text {wedge }}}{2} & \mathrm{~F}=\frac{\cos (\alpha)+f \sin (\alpha)}{\sin (\alpha)-f \cos (\alpha)} \frac{F_{\text {wedge }}}{2} \\
u=2 \operatorname{tg}(\alpha) u_{\text {wedge }} & u=2 \operatorname{tg}(\alpha) u_{\text {wedge }}
\end{array}
$$

\subsubsection{In situ observation and image correlation}

In order to quantify the change over time of the in-plane displacements on this surface, a speckle-like pattern with an average particle diameter of $25 \mu \mathrm{m}$ was generated by sand blasting. A CCD camera and an optical lens allow in situ observation of a region of $5 \times 4 \mathrm{~mm}^{2}$ close to the notch. A typical test corresponds to about 200 frames between the start of the wedge load and final catastrophic failure.

Digital Image Correlation has been used to quantity displacement field. A subset-based approach computing the correlation product of squared rigid 64_64 pixels subsets leads to an accuracy of 0.015 pixel [23]. A Cross-Section discretization of the experimental displacement field between two frames is obtained by computing the rigid displacements of a grid of subsets, regularly spaced with a period of 5 pixels, forming a grid of 243_192 pixels. This operation is performed between all successive frames.

\subsection{Crack Tip Opening Angle (CTOA) and energy dissipation rate $R$}

\subsubsection{Crack Tip Opening Angle CTOA}

The current crack front is defined as the most extreme point exhibiting a significant difference in gray level between two successive frames [23]. The current position of the crack tip is identified for each frame recorded during crack growth. The Crack Opening Displacement (COD) is determined from two points located at a distance $l=2$ mm behind the crack tip, and symmetrically located on the upper and lower side of the crack (red crosses on the Fig. 3). The displacement of these points is then tracked until the beginning of the frame sequence (blue crosses in the Fig. 3), thus defining the COD as the sum of the vertical displacements of these two points $\operatorname{COD}=\delta_{1}+\delta_{2}$. The size of the image subset used to track the upper and lower points is displayed as a black square on Fig. 3.

\subsubsection{The energy dissipation rate $R$} by

For an increment dA of the crack surface, the energy dissipation rate $R$ and variation $C$ of the potential energy ( $\pi$ ) are given

$$
R=\frac{\mathrm{dU}_{d}}{\mathrm{dA}} \quad C=-\frac{d \pi}{\mathrm{dA}}=\frac{d\left(W_{\mathrm{ext}}-U_{e}\right)}{\mathrm{dA}}
$$

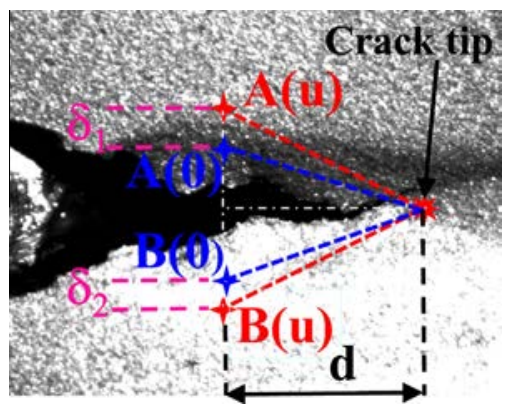

Fig. 3. Determining the crack opening displacement (COD). The star indicates the current position of the crack front. Red crosses define current positions of the points and blue crosses the corresponding positions in the initial configuration. The crack opening angle is defined by arctan $\left(\left(\delta_{1}+\delta_{2}\right) / d\right)$. (For interpretation of the references to colour in this figure legend, the reader is referred to the web version of this article.) 
where $W_{\text {ext }}$ and $U_{e}$ correspond respectively to the total work of the external loads and elastic energy. $U_{d}$ is the total energy dissipated in the fracture process (plastic dissipation and fracture energy). During crack growth, $C=R$ [6], thus

$$
\frac{\mathrm{d} W_{\text {ext }}}{\mathrm{dA}}-\frac{\mathrm{d} U_{e}}{\mathrm{dA}}=\frac{\mathrm{d} U_{d}}{\mathrm{dA}}=R
$$

Three different measures of the dissipation rate $R$ (Fig. 4) may be defined. $R_{\text {stable }}$ and $R_{\text {unstable }}$ correspond to stable crack growth and final failure respectively. $R_{\text {stable }}$ and $R_{\text {unstable }}$ may be ascertained by the wedge test, if a relation between the observed crack length and the current fractured area is known. $R_{\text {global }}$ corresponds to the ratio of the total energy used to fracture the sample $\left(W_{\text {ext }}\right)$ and the total crack area $\left(A_{\text {fractured }}\right)$.

$$
R_{\text {global }}=\frac{W_{\text {ext }}}{A_{\text {fractured }}}
$$

The total work is known from the load displacement curve and the fractured area may be measured post mortem by simple optical observation. It is thus easy to determine $R_{\text {global }}$ for the crack fronts of any shape.

In the present paper we demonstrate that the:

- wedge test proposed leads to stable crack propagation in spot welds with self-similar shapes of the crack front;

- combined knowledge of the crack tip opening angle (CTOA) and the overall energy dissipation rate $R_{\text {global }}$ can provide reliable values of the cohesive zone parameters $\left(\Gamma_{\text {coh }}\right.$ and $\left.\sigma_{c o h}\right)$;

- combined knowledge of CTOA with $R_{\text {global }}$ may be used to systematically classify industrial spot welds.

\section{The mechanical model}

The crack propagation in the fusion zone has been modeled by cohesive zones. Then, the mechanical model is used to predict the fracture energy $\Gamma_{\text {coh }}$ and the fracture strength $\sigma_{c o h}$.

\subsection{Geometry and loading}

The initial state of the two sheet metals joined by a circular spot weld is modeled. The geometry of this model with the boundary conditions is represented on Fig. $5 \mathrm{a}$. The apparent length of the joint is $d=7.1 \mathrm{~mm}$ with a width $b_{n}=2 \mathrm{~mm}$. The

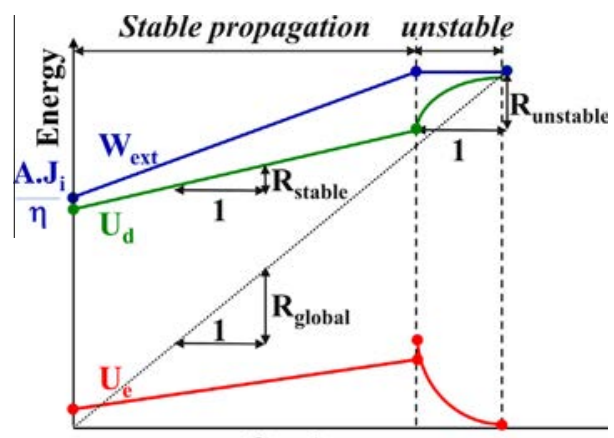

Crack area

Fig. 4. External work $\left(W_{e x t}\right)$, stored energy $\left(U_{e}\right)$ and dissipated energy $\left(U_{d}\right)$ as functions of the crack area. Different measures of the energy release rate $R$.

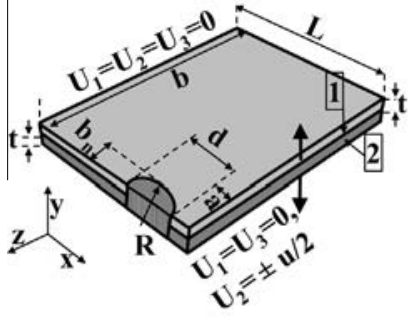

(a)

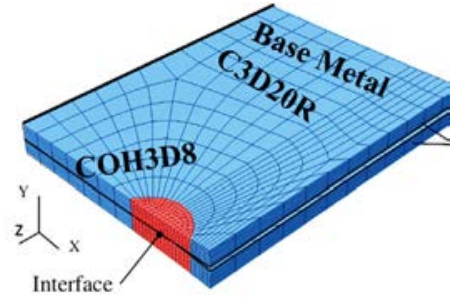

(b)

Fig. 5. Finite element model of the wedge test: Geometry, boundary conditions (a) and mesh (b). 
dimensions of the steel sheet are $L=25 \mathrm{~mm}$ and $b=40 \mathrm{~mm}$. Displacement of the two long edges is controlled. On the edge close to the joint, the opening displacement is applied, whereas the opposite edge is pinned down.

\subsection{Finite element mesh}

As normal, finite elements were chosen to evaluate the stress strain history of the assembly. These finite element calculations were done with abaqus standard. The sheets and the joint were meshed with hexahedral C3D20R elements (20 nodes/8 Gauss points). Each sheet corresponds to 8 layers of elements of equal thickness. Mesh refinement in the fusion zone leads to typical element dimensions of $0.45 \times 0.25 \times 0.25 \mathrm{~mm}^{3}$. The joint interface is represented by an unstructured mesh of $0.1 \mathrm{~mm}$ thick COH3D8 cohesive elements (Fig. 5b). Elements at the joint and sheet surfaces are tied together.

\subsection{Material behavior}

Our work focuses on weld nugget fractures. Hence, the only role of the heat affected zones is to transmit the load to the fusion zone. The mechanical behavior of the heat affected zones was assumed close to the base material. Numerical testing showed that this has no influence on the model results. The stress strain relations for the base metal and the fusion zone material of DP780 have been determined by uniaxial compression tests. Linear strain hardening describes with enough accuracy the experimental data (Fig. 6a).

$$
\sigma_{=} \sigma_{0}\left(1+n \varepsilon_{p}\right)
$$

The yield stress of the base and the fusion zone materials are respectively $400 \mathrm{MPa}$ and $1300 \mathrm{MPa}$. The base metal exhibits a strain hardening $n=2$ and the fusion zone material $n=0.2$.

The behavior of the cohesive elements is shown on Fig. $6 \mathrm{~b}$. This represents the normal stress component $\sigma_{n}$ as a function of the cohesive displacement $\delta$. For mixed-mode loading, the following failure criterion is used

$$
\left(\frac{\left\langle\sigma_{n}\right\rangle}{\sigma_{c o h}}\right)^{2}+\left(\frac{\sigma_{c 1}}{\sigma_{c o h}}\right)^{2}+\left(\frac{\sigma_{c 2}}{\sigma_{c o h}}\right)^{2}=1\langle x\rangle= \begin{cases}x & \text { for } x>0 \\ 0 & \text { for } x<0\end{cases}
$$

Damage is simulated by a linear decrease of cohesive strength with its displacement. Note that these elements are considered fully fractured, when their entire energy is dissipated, and thus reached a null cohesive strength. The stiffness $E_{\text {coh }}$ was fixed to $10^{9} \mathrm{MPa} / \mathrm{mm}$. The cohesive energy $\Gamma_{\text {coh }}$ is thus related to the cohesive stress by

$$
\Gamma_{\text {coh }}=\frac{\sigma_{\text {coh }} \delta}{2}
$$

In the following, we will use $\Gamma_{\text {coh }}$ and $\sigma_{\text {coh }}$ to characterize weld strength. As experimental observations reveal only little or negligible contribution from shear failure, no particular value has been assigned to the shear resistance. This approach limits the number of parameters in the cohesive zone to take into account.

Ascertaining CTOA in the F.E. - model is explained in Fig. 7. The area $A$ of the broken interface is illustrated in blue. First, the crack opening $d_{0}$ is identified at a distance $l=2 \mathrm{~mm}$ of the crack tip by interpolating the vertical displacement of the nodes. Lacroix et al. (2012) showed that $l=2 \mathrm{~mm}$ is the optimum distance for determining the crack opening $d_{0}$. Then the CTOA is determined by CTOA $=\arctan \left(d_{0} / 2\right)$.

\section{Results}

\subsection{Experimental results for spot welds DP600GI}

The progression of the crack front during wedge indentation was observed by interrupting the tests at nine intervals. After wedge indentation, the samples once cooled by liquid nitrogen were split by a chisel. Fig. 8 shows the

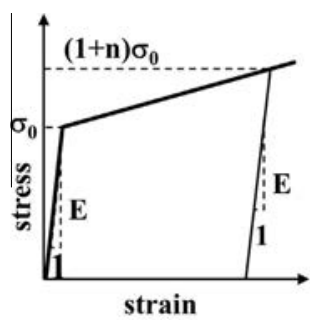

(a)

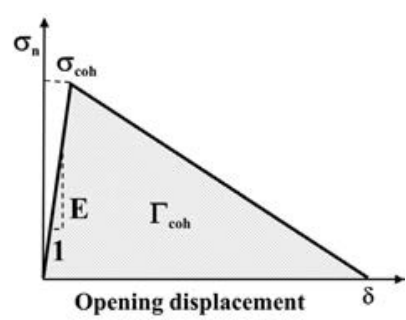

(b)

Fig. 6. Material behavior in the F.E.-model. (a) structure (Base metal, Heat Affected Zone and Fusion zone), (b) interface (cohesive zone elements). 


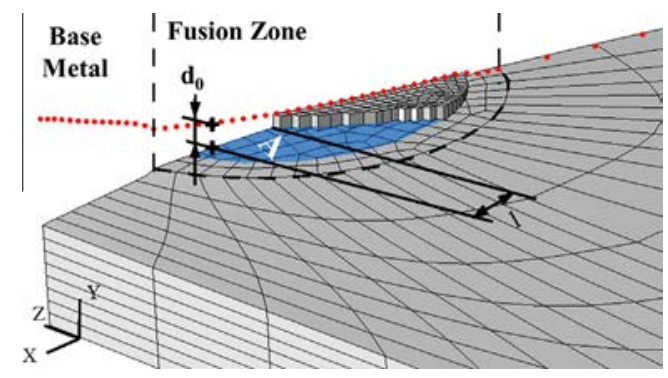

Fig. 7. Determination of the Crack Tip Opening Angle (CTOA) in the F.E. - model. The area $A$ of the interface is illustrated in blue. The opening $d_{0}$ is given by the vertical displacement interpolated between the nodes at a distance $l=2 \mathrm{~mm}$ from the crack tip. (For interpretation of the references to colour in this figure legend, the reader is referred to the web version of this article.)

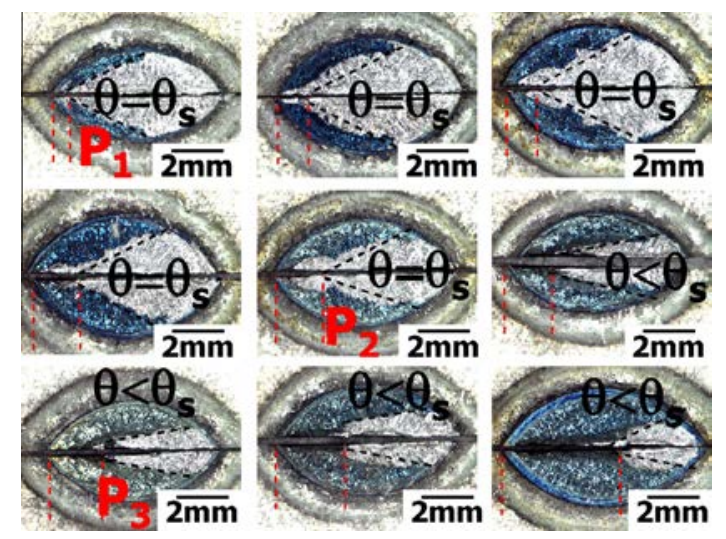

Fig. 8. Optical observations of the crack front and fractured area (in blue) after interrupted wedge indentations on 9 different samples. (For interpretation of the references to colour in this figure legend, the reader is referred to the web version of this article.)

evolution of the crack front with the wedge displacement. A quasi "self-similar" crack front propagating at constant angle with the free surface was observed. This propagation at constant angle provides a simple relation between the crack area and length. Fig. 9 shows SEM observations of the fracture surface. The wedge direction is indicated on the observation. The crack propagation starts in pure mode I. The surface exhibits both ductile (cup and cone) and brittle cleavage failure. Close to the free surface, mode II failure is observed. The area corresponding to mode II failure is limited. Mode II failure becomes significant at the end of crack propagation as can be confirmed by the existence of $45^{\circ}$ flanges.

The existence of self-similar crack fronts and the limitation of shear failure, can furnish relevant values of the dissipation rate during stable crack propagation $\left(R_{\text {stable }}\right)$ and of the overall dissipation rate $\left(R_{\text {global }}\right)$. Certainly, the dissipation rate corresponding to instable crack propagation $\left(R_{\text {instable }}\right)$ may be affected by the shear failure. However, this dissipation rate is not used in the work presented since as will be proven later that the global dissipation rate classifies perfectly any industrial weld considered. Fig. 10a illustrates a typical load displacement curve. The total energy $W_{\text {ext }}$ is the area under the curve (shaded in blue). The overall dissipation rate $\left(R_{\text {global }}\right)$ corresponds to the ratio of the total energy over the area fractured. The crack advance " $a$ " (black line) observed by in situ observation is shown on the same figure. A minimum opening displacement is required to generate a crack visible at the free surface corresponding to a "stationary" regime with the crack front propagating at constant angle. Fig. 10b shows the variation of the crack opening angle with the crack length. For crack lengths smaller than $1 \mathrm{~mm}$, the crack opening angle has not been studied, since they are considered too short to be significant. The CTOA exhibits a plateau $\mathrm{P}_{1} \mathrm{P}_{2}$. The corresponding points are indicated on Figs. 10a and 9a. The plateau value of the CTOA corresponds to quasi "stationary" crack propagation with a crack front making a constant angle with the propagation direction. This plateau, characterizing stable crack propagation, is only slightly affected by shear mode failure since there are no $45^{\circ}$ flanges between P1 and P3. (Fig. 9a). The region $\mathrm{P}_{2} \mathrm{P}_{3}$ on Fig. 9a exhibits shear failure and it is exceedingly small. The corresponding points are plotted in Figs. 10a, b. The overall load varies continuously over $\mathrm{P}_{1} \mathrm{P}_{3}$ and the CTOA decreases in $\mathrm{P}_{2} \mathrm{P}_{3}$. This clearly shows, that, in the present case, the fracture energy is not affected by the small area submitted to mode II failure and the CTOA only varies slightly. 


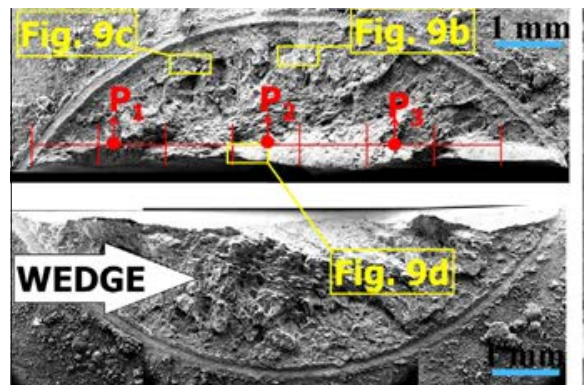

(a)

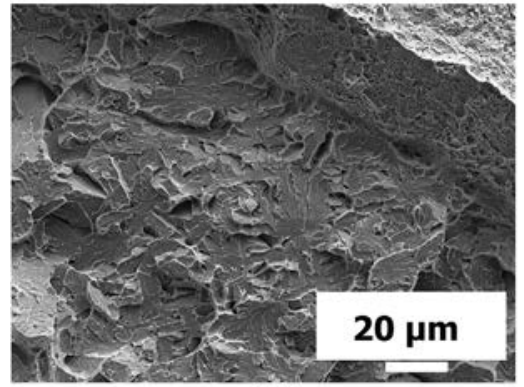

(c)

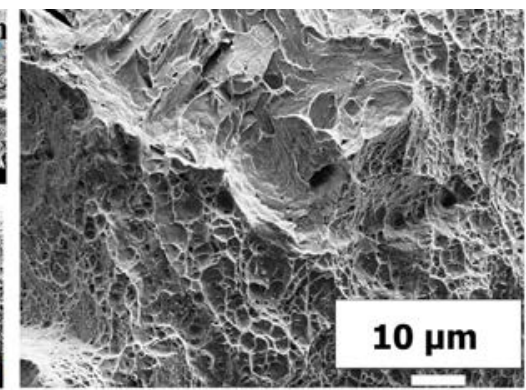

(b)

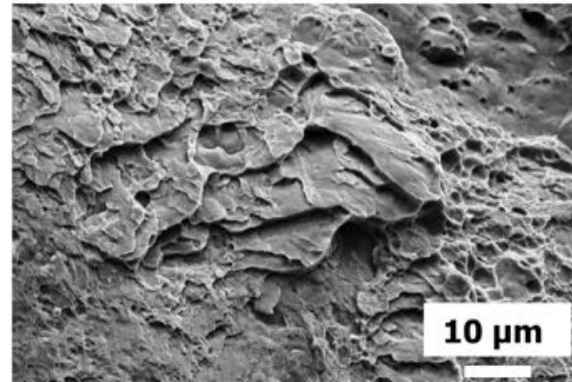

(d)

Fig. 9. SEM observations of the fractured surface on a DP600GI spot weld after wedge indentation. (a) complete specimen, examples of (b) ductile area, (c) brittle area, (d) shear mode failure. Between $\mathrm{P}_{1}$ and $\mathrm{P}_{2}$ the crack propagates at constant CTOA (Fig. 10).

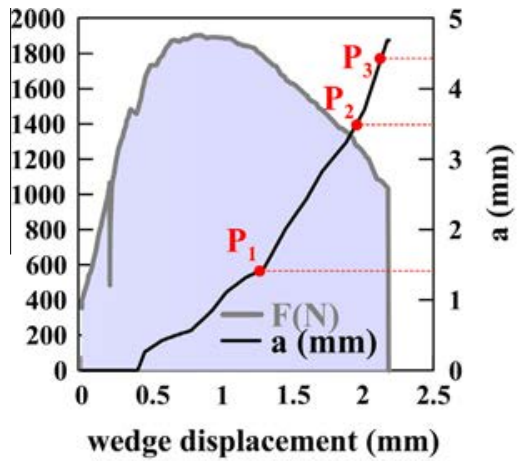

(a)

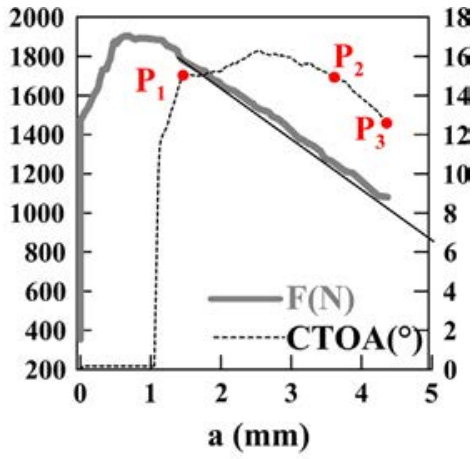

(b)

Fig. 10. Wedge test on DP600GI. Load (F) and crack advance (a) vs. wedge displacement (a), load (F) and crack opening angle (CTOA) vs. crack advance (b).

\subsection{Parametric analysis of spot weld failure}

The experimental work on DP600GI spot welds shows that wedge indentation leads to stable crack propagation with "self-similar" crack fronts. The wedge test provides reliable measurements of the overall energy dissipation rate $R_{\text {global }}$ and the crack tip opening angle CTOA. One major question that remains is the transferability of these measurements for different shapes and different mismatches between the flow stresses of the base material and the fusion zone material. This question and related issues are subsequently addressed by the mechanical model.

First, the mechanical model was applied to the DP600GI spot weld. Fig. 11 shows the crack shape as a function of the wedge displacement. The "self-similar" propagation with a crack front at constant angle to the propagation direction is well reproduced. The maximum load depends on the particular microstructure of the specimen. Fig. 12 shows a comparison between the experimental load displacement curve and the simulation results. The model overestimates the maximum load, but the total energy (shaded in blue) is a satisfactory estimation. When changing the test samples, maximum load can vary dramatically yet the total energy values remain fairly constant. The CTOA exhibits the same plateau value in the mechanical model and the experimental data. Thus, the total energy needed for failure and the plateau value of the CTOA are reproducible results. 


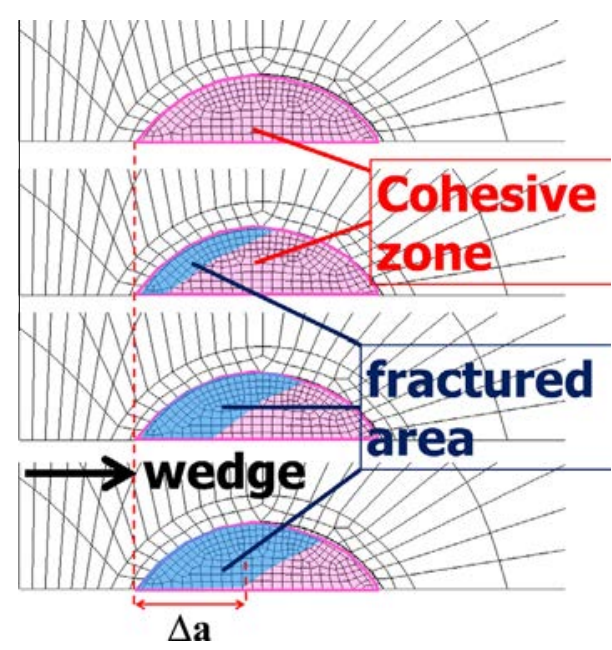

Fig. 11. F.E. - model of crack propagation in DP600GI spot weld. Crack front and fractured area at different stages of the wedge indentation.

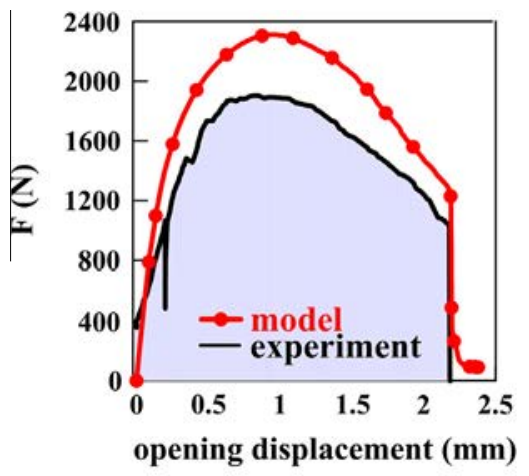

(a)

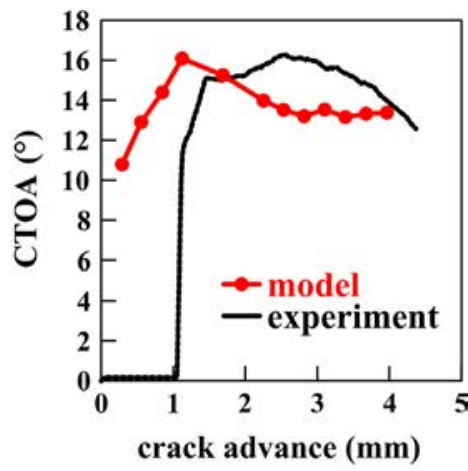

(b)

Fig. 12. Comparison of experimental results and simulation for the DP600GI spot weld. Load $(F)$ and crack advance vs. wedge displacement (a), Load $(F)$ and crack opening angle (CTOA) vs. crack advance (b).

As argued previously, due to the limited influence of mode II failure, the experimental values of the total energy release rate $R_{\text {global }}$ and the crack tip opening angle are only slightly affected by the specimen dimensions. Fig. 13 shows the variation of the overall energy dissipation rate $R_{\text {global }}$ and the crack tip opening angle CTOA with the cohesive stress and with the cohesive energy. The total energy dissipation rate $R_{\text {global }}$ varies significantly with both, the cohesive stress $\sigma_{c o h}$ and the cohesive energy $\Gamma_{\text {coh }}$. The CTOA depends essentially on the cohesive energy.

Fig. 14 shows the influence of the yield stress ratio (mismatch $\sigma_{0}^{F . Z .} / \sigma_{0}^{B . M .}$ ) on the overall energy dissipation rate $R_{\text {global }}$ and on the crack tip opening angle CTOA. The results correspond to a cohesive strength $\sigma_{\text {coh }}=1300 \mathrm{MPa}$ and a cohesive energy $\Gamma_{\text {coh }}=60 \mathrm{~kJ} / \mathrm{m}^{2}$. If the yield stress of the base material is smaller than the cohesive stress, both, $R_{\text {global }}$ and CTOA, vary strongly with the yield stress (fusion zone or base material). Large values of the base material yield stress lead to quasi constant values of $R_{\text {global }}$ and CTOA. The influence of the mismatch on the critical CTOA is negligible. The influence of the mismatch on the overall energy release rate is significant for small values of the yield stress (either base material or fusion zone material).

For small yield stresses compared to the cohesive strength, the influence of the mismatch should be regarded. This way, the combined knowledge of $R_{\text {global }}$ and CTOA can yield both cohesive energy $\Gamma_{\text {coh }}$ and its strength $\sigma_{c o h}$.

\subsection{Classification of industrial spot welds by the wedge indentation test}

The mechanical behavior of Advanced High-Strength Steel spot welds is a key-point for the development of new grades of AHSS. One of the foremost methods for evaluating the mechanical strength of spot welds is the Cross Tensile test (Fig. 15). This test leads to several criteria for the acceptability of the spot weld. The two major ones are the cross tensile Strength (CTS) and the failure type (button pull out, or interfacial failure). Although full interfacial failures are now largely accepted, button pullout in the base metal or in the heat affected zone is usually preferred because it is easier to characterize. 


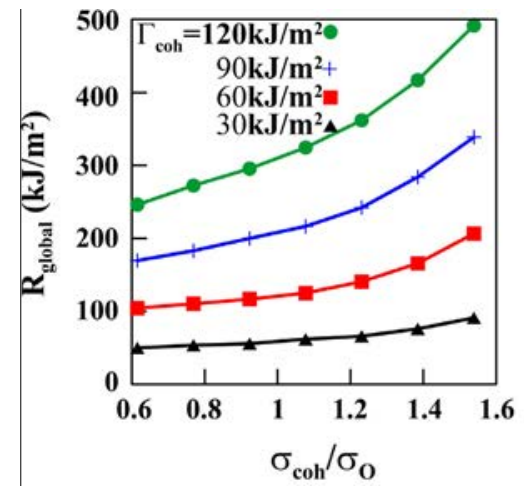

(a)

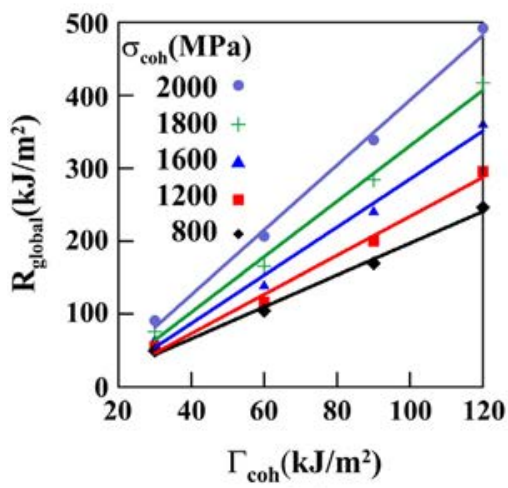

(c)

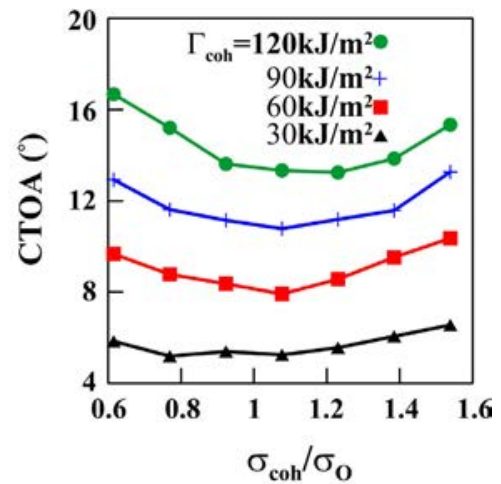

(b)

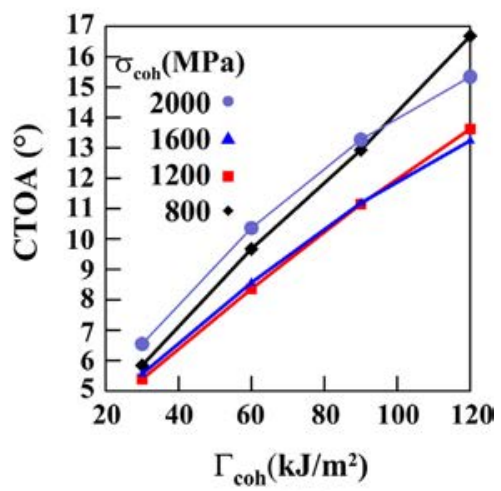

(d)

Fig. 13. Parametric analysis of crack propagation. Influence of the cohesive stress $\left(\sigma_{\text {coh }}\right)$ on the overall energy dissipation rate $\left(R_{\text {global }}\right)$ and the crack opening angle (CTOA) (a, b). Influence of the fracture energy $\left(\Gamma_{\text {coh }}\right)$ on the energy dissipation rate $\left(R_{\text {global }}\right)$ and the crack opening angle $(\mathrm{CTOA})(\mathrm{c}, \mathrm{d})$.

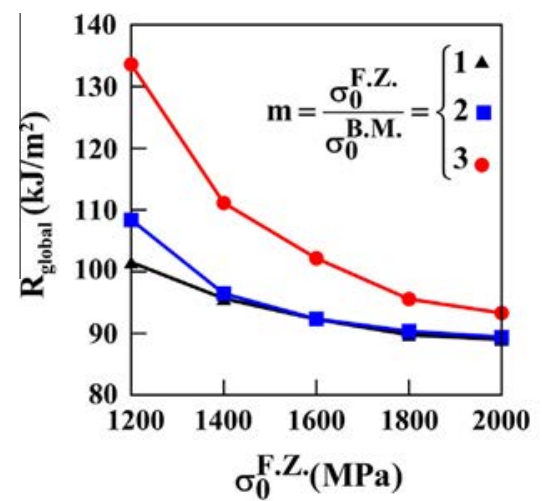

(a)

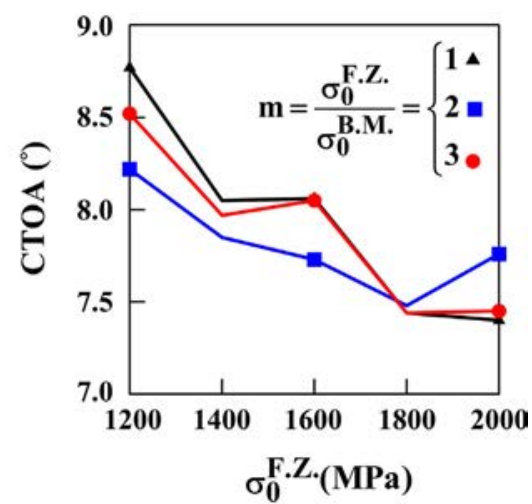

(b)

Fig. 14. Parametric analysis of crack propagation. Influence of the mismatch $\left(m=\sigma_{0}^{F . Z .} / \sigma_{0}^{B . M .}\right.$ ) on the energy dissipation rate (a) and the crack opening angle (b).

Nevertheless, interfacial failures are observed on welds with well-developed fusion zones and exhibiting good CTS levels [24].

In the this section, the wedge test results (values of $R_{\text {global }}$ and CTOA) are compared to the classification obtained by the standard Cross Tensile Test. $2 \mathrm{~mm}$ thick sheets of three commercial Dual Phase steel grades and two commercial TRIP steel grades were resistance spot welded corresponding to EN ISO 18278-2. Three synthetic alloys of 2 mm thickness were performed at the Arcelor Research Center. Carbon and phosphorus vary between the three grades. The phosphorus content fluctuates significantly below and above the levels typically used in the commercial grades. These plates are not coated. LCLP 


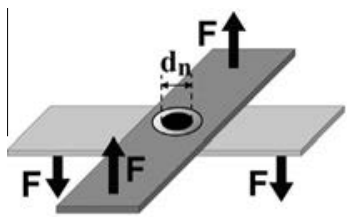

(a)

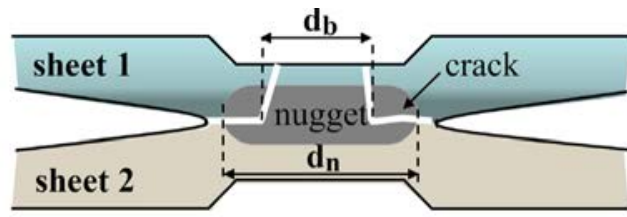

(b)

Fig. 15. Schematic representation of the Cross Tensile test, with the nugget $\left(d_{n}\right)$ and button $\left(d_{b}\right)$ diameter.

Table 1

Steel grades used for the comparison between Cross Tensile Test results and wedge test results. IClP means low carbon and low phosphorus content, ICllP means low carbon and very low phosphorus content.

\begin{tabular}{|c|c|c|c|c|c|c|c|c|}
\hline \multirow{2}{*}{$\begin{array}{l}\text { Welding } \\
\text { Grade }\end{array}$} & \multicolumn{3}{|c|}{ Cross tensile test } & \multicolumn{5}{|l|}{ Wedge test } \\
\hline & Current (kA) & (Load) daN & Button ratio $d_{b} / d_{n}$ & Number of Samples & joint radius (mm) & Joint area $\left(\mathrm{mm}^{2}\right)$ & $R\left(\mathrm{~kJ} / \mathrm{mm}^{2}\right)$ & $\operatorname{CTOA}\left({ }^{\circ}\right)$ \\
\hline DP1 & 10.7 & 1600 & 1.0 & 8 & 4.11 & 5.82 & 425 & 16.6 \\
\hline \multirow[t]{2}{*}{ DP2 } & 9.0 & 1300 & 0.75 & 8 & 3.19 & 4.58 & 352 & 13.4 \\
\hline & 10 & 1600 & 0.65 & 7 & 4.07 & 5.33 & 314 & 13.3 \\
\hline \multirow[t]{2}{*}{ DP3 } & 7.7 & 700 & 0.0 & 9 & 2.68 & 7.91 & 124 & 8.8 \\
\hline & 9.9 & 1100 & 0.8 & 8 & 3.33 & 6.42 & 243 & 13.3 \\
\hline TRIP1 & 9.0 & 1200 & 0.75 & 3 & 3.40 & 6.92 & 180 & 10.3 \\
\hline TRIP2 & 9.0 & 1100 & 0.5 & 17 & 3.82 & 9.32 & 168 & 9.2 \\
\hline TRIP3.1 & - & - & - & 17 & 3.82 & 9.32 & 168 & 9.2 \\
\hline TRIP3.2 & - & - & - & 17 & 3.82 & 9.32 & 168 & 9.2 \\
\hline ICllP & 10.1 & 1700 & 1.0 & 8 & 4.17 & 10.54 & 475 & 21.6 \\
\hline ICIP & 9.2 & 1600 & 1.0 & 5 & 3.52 & 8.57 & 513 & 22 \\
\hline lChP & 8.4 & 800 & 0.7 & 6 & 3.84 & 11.08 & 77 & 7 \\
\hline
\end{tabular}

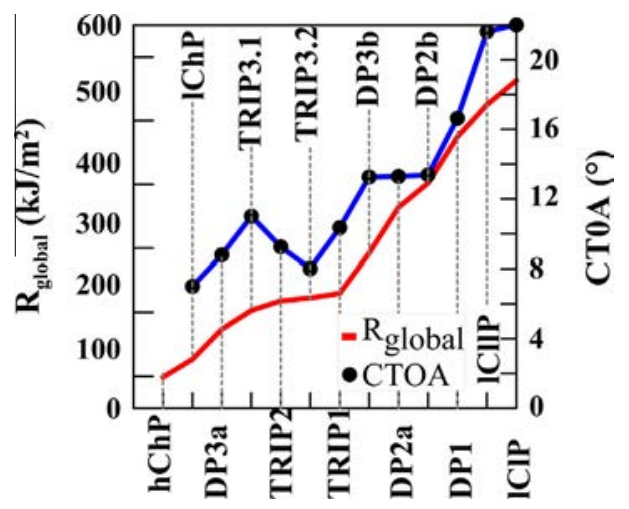

Fig. 16. Experimental results for industrial spot welds $R_{\text {global }}$ and crack opening angle CTOA.

was designated to mean low carbon and phosphorus, while HCHP meant high levels of carbon and phosphorus. The results of the cross tension test and the wedge indentation are summarized in Table 1.

Fig. 16 gives the classification of the different grades as a function of the overall energy dissipation rate. As expected, synthetic alloys occupy the limits of the classification. High phosphor contents bring about the smallest energy dissipation rates and low phosphor contents exhibit the largest values of $R_{\text {global }}$. Comparing the variation of $R_{\text {global }}$ and CTOA between different grades, provide deeper insight in the fracture behavior as the CT-result. The close variation (almost parallel curves) of $R_{\text {global }}$ and CTOA indicates a significant variation of the fracture energy $\Gamma_{\text {coh }}$ and a smaller variation of the fracture stress between the different grades.

Figs. 17 and 18 compare the wedge test results with the cross tensile classification of the different grades. The classifications given by the cross tensile test and by the wedge test correspond well, but you have a finer sensitivity with the new test. The two results for the DP2 grade illustrate and explain the significant influence of the welding current intensity on the cross tensile behavior. The overall energy dissipation rate and the CTOA do not vary significantly between $9 \mathrm{kA}$ and $10 \mathrm{kA}$. Hence, the fracture energy and the cohesive stress may thus be assumed very close. Furthermore, the significant variation of the cross tensile strength must thus be attributed to the difference in area of the spot welds. Indeed, normalizing the cross tensile strength by the joint area would lead to quasi identical results. The wedge test leads naturally to normalized values of the fusion zone strength. 


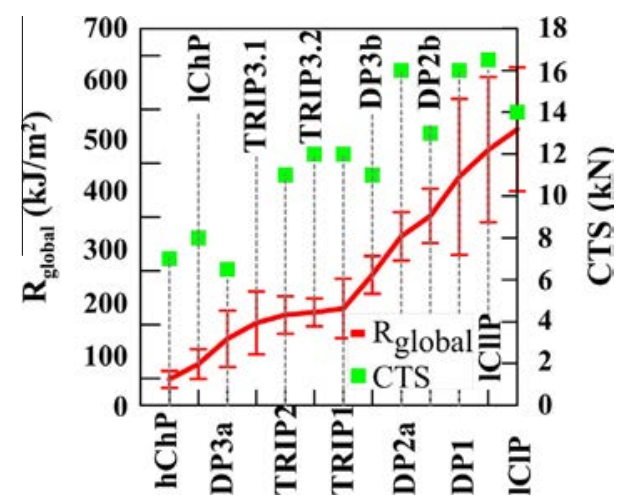

Fig. 17. Experimental results for industrial spot welds. Comparison between $R_{\text {global }}$ and Cross Tensile Strength (CTS).

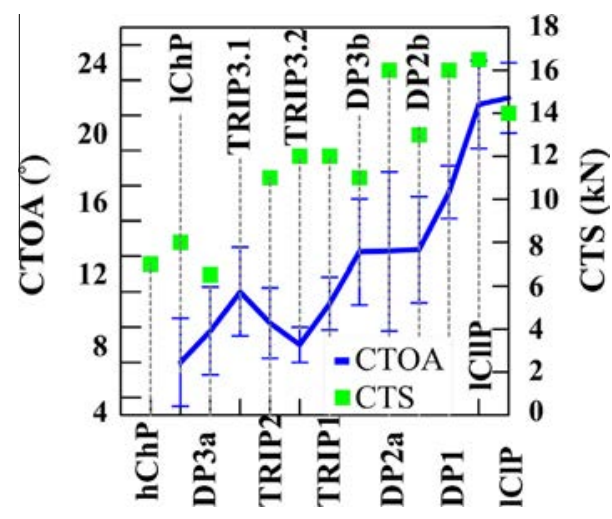

Fig. 18. Experimental results for industrial spot welds. Comparison between CTOA and Cross Tensile Strength (CTS).

\section{Conclusions}

Crack propagation in heterogeneous materials was studied by and experimental approach and subsequent mechanical modeling. A first of its kind novel wedge test with optical in situ observation of the crack length has been developed and applied to commercial and synthetic grades of AHSS. The wedge test provided stable crack propagation with both

- quasi self-similar crack fronts forming a constant angle with the crack propagation direction

- limited influence of mode II fracture at the free surface.

We want to emphasize that the wedge test developed was able to characterize perfectly with any assumptions stable crack propagation by two direct measurements, i.e. the overall energy dissipation rate $R_{\text {global }}$ and the crack tip opening angle CTOA.

In addition, employing finite elements, a mechanical model was built which can determine relevant values for the fracture energy $\Gamma_{\text {coh }}$ and the fracture stress $\sigma_{\text {coh }}$. The model does overestimate the maximum load, but the total energy is satisfactory. Future work might deal with variations of $\Gamma_{\text {coh }}$ and $\sigma_{\text {coh }}$ due to the local microstructure. This should lead to better load displacement curves.

\section{Acknowledgments}

The authors thank Professor David Embury for his valuable suggestion to work with a wedge test and Chris Yukna for his help in proofreading \& advice on editing.

\section{References}

[1] Zhang H, Senkara J. Resistance welding, fundamentals and applications. Chapter 8, Taylor \& Francis Group; 2006. ISBN-13: 978-0-8493-2346-1.

[2] Griffith AA. The phenomenon of rupture and flow in solids. Philos T Roy Soc 1921;A221:163-98.

[3] Rice JR. A path independant integral and the approximate analysis of strain concentration by notches and cracks. J Appl Mech T ASME 1968;35:379-86. 
[4] Memhard D, Brocks W, Fricke S. Characterization of ductile tearing resistance by energy dissipation rate. Fatigue Fract Eng Mater Struct $1993 ; 16(10): 1109-24$.

[5] Turner CE. A re-assessment of ductile tearing resistance, Part: I the geometry dependence of J-R curves in fully plastic bending. Part II: Energy dissipation rate and associate R curves on normalized axes. In: Firraro D, editeur, Fracture behaviour and design of materials and structures, vol. 2. Warley, 1990.

[6] Turner CE, Koloednik 0. A micro and macro approach to the energy dissipation rate model of stable ductile crack growth. Fatigue Fract Eng Mater Struct $1994 ; 17(9): 1089-107$.

[7] Li ZF, Turner CE. Crack-opening angle and dissipation-rate analysis of R-curves for side grooved pieces of HY130 steel in bending. J Mater Sci $1993 ; 28(21): 5922-30$.

[8] Brocks W, Anuschewski P, Hellmann D. A concept for scaling JR-curves by plastic constraint factors. Int J Fract 2004;130(1):455-69.

[9] Cotterell B, Reddel JK. The essential work of plane stress ductile fracture. Int J Fract 1977;13(3):267-77.

[10] Pardoen T, Marchal Y, Delannay F. Thickness dependence of cracking resistance in thin aluminium plates. J Mech Phys Solids 1999;47(10):2093-123.

[11] Cotterell B, Pardoen T, Atkins AG. Measuring toughness and the cohesive stress-displacement relationship by the essential work of fracture concept. Eng Fract Mech 2005;72(6):827-48.

[12] Newman JCM, James A, Zerbst U. A review of the CTOA/CTOD fracture criterion. Eng Fract Mech 2003;70(3-4):371-85.

[13] Heerens J, Schödel M. Characterization of stable crack extension in aluminium sheet material using the crack tip opening angle determined optically and by the [delta]5 clip gauge technique. Eng Fract Mech 2009;76(1):101-13.

[14] Shih CF, de Lorenzi HG, Andrews WR. Studies on crack initiation and stable crack growth. ASTM STP 1979;668:65-120.

[15] Kanninen MF, Rybicki EF, Stonesifer RB, Broek D, Rosenfield AR, Nalin GT. Elastic-plastic fracture mechanics for two dimensional stable crack growth and instability problems. ASTM STP 1979;668:121-50.

[16] Newman Jr JC. An elastic-plastic finite element analysis of crack initiation, stable crack growth, and instability; 1984 . ASTM STP833:93-117.

[17] Newman Jr JC, Shivakumar KN, McCabe DE. Finite element fracture simulation of A533B steel sheet specimens. In: Defect assessment in components fundamentals and applications, 9. ESIS Publication; 1991. p. 117-26.

[18] Sutton MA, Helm JD, Boone ML. Experimental study of crack growth in thin sheet 2024-T3 aluminum under tension-torsion loading. Int J Fract $2001 ; 109(3): 285-301$.

[19] Atkins AG, Chen Z, Cotterell B. The essential work of fracture and JR curves for the double cantilever beam specimen: an examination of elastoplastic crack propagation. Proc Roy Soc Lond A Mater 1998;454(1971):815-33.

[20] Dugdale DS. Yielding of steel sheets containing slits. J Mech Phys Solids 1960;8(2):100-4.

[21] Barenblatt GI. The mathematical theory of equilibrium cracks in brittle fracture. Adv Appl Mech 1962;7:55-129.

[22] Zhou B, Thouless MD, Ward SM. Predicting the failure of ultrasonic spot welds by pull-out from sheet metal. Int J Solids Struct 2006;43(2526):7482-500.

[23] Lacroix R, Lens A, Kermouche G, Bergheau JM, Klocker H. Determination of CTOA in the molten material of spot welds using the digital image correlation technique Eng. Fract Mech 2012;86. 48-5.

[24] Dancette M, Dupuy T, Lens A, Nait Oultit. B, Massardier V, Fabrègue D, Klocker H. An investigation of failure types in high-strength steel resistance spot. Weld World 2010;54(3-4):1-14.

[25] Payen GR, Klocker H, Lens A, Wilkinson DS, Embury JD. Design of an in situ mechanical test for spot-welded joints. Eng Fract Mech 2012;96:528-38. 